\title{
Online Chinese Reading Practice Platform for Social Integration of Ethnic Minority Students in Hong Kong
}

\author{
Kat Leung, Y H Chan and Ho Man Koon
}

\begin{abstract}
This paper is an interim report on an on-going funded research project designed and launched to assist secondary school students from ethnic minorities in Hong Kong to integrate into the local community by achieving a higher proficiency level in written Chinese through enhancing their reading abilities on a specially designed online Chinese Reading Platform.

The Chinese Reading Package for the students offers short but captivating passages whose subject matter and contents relate closely to everyday lives of these students generally, so that students will not find it foreign and remote. The passages were categorized into six levels. Such a design has been intended to cater to different levels and therefore genuine needs of individual students working on the platform, at their own pace.

The conclusion of the first stage will be marked by analyzing the data from the pre-test and post-test on students' performance, administering a feedback questionnaire to participating students and teachers and conducting focus group interviews, to achieve the effect of triangulation of the study.
\end{abstract}

Keywords - Chinese as foreign language, e-learning platform in Chinese comprehension, social integration of Ethnic Minority students in Hong Kong

\section{INTRODUCTION}

In recent years considerable attention has been paid to difficulties encountered by young students from ethnic minority families in Hong Kong in their second language acquisition (namely Chinese). Sufficient research has revealed that these students may be able to speak Cantonese quite fluently, but their reading ability and written Chinese leaves a lot to be desired, leaving the majority way off the passable mark as compared to local students in the same age group. It is precisely their low level of written Chinese that is going to hamper their advancement in society in the future, both in terms of social integration and in terms of career opportunities

Kat LEUNG, Caritas Institute of Higher Education, Hong Kong E-mail: kleung@cihe.edu.hk and prospects.

In the view of prominent researchers, by enhancing classroom teaching alone will not solve the problem, since for quite a few of these students from ethnic minority backgrounds have already lost the interest in reading to them rather boring and examination-oriented types of passages/texts taught in class. Research has demonstrated that what is badly needed to improve the situation and to help these students raise their proficiency level in Chinese all round, first and foremost, is to motivate them to read again.

The research team of this project has therefore pondered the problem, explored the background to the problem and then come up with a brilliant solution, namely, to design and launch a self-instructional on line Chinese reading platform to be uploaded for students to use, do exercises relating to the reading and benefit from immediate and culminating feedback. The platform has thus been tested, trialed and piloted with a group of ethnic minority students from four different participating schools to date. This paper therefore is an interim report on the background, design and launch of this platform on the following pages.

In recent years considerable attention has been paid to difficulties encountered by young students from ethnic minority families in Hong Kong in their second language acquisition (namely Chinese). Sufficient research has revealed that these students may be able to speak Cantonese quite fluently, but their reading ability and written Chinese leaves a lot to be desired, leaving the majority way off the passable mark as compared to local students in the same age group. It is precisely their low level of written Chinese that is going to hamper their advancement in society in the future, both in terms of social integration and in terms of career opportunities and prospects.

In the view of prominent researchers, by enhancing classroom teaching alone will not solve the problem, since for quite a few of these students from ethnic minority backgrounds have already lost the interest in reading to them rather boring and examination-oriented types of passages/texts taught in class. Research has demonstrated that what is badly needed to improve the situation and to help these students raise their proficiency level in Chinese all round, first and 
foremost, is to motivate them to read again.

The research team of this project has therefore pondered the problem, explored the background to the problem and then come up with a brilliant solution, namely, to design and launch a self-instructional on line Chinese reading platform to be uploaded for students to use, do exercises relating to the reading and benefit from immediate and culminating feedback. The platform has thus been tested, trialed and piloted with a group of ethnic minority students from four different participating schools to date. This paper therefore is an interim report on the background, design and launch of this platform on the following pages.

\section{BACKGROUND}

Research has revealed that in the early stage of their schooling, young students from ethnic minority backgrounds do not perform worse than their local counterparts in Chinese language reading and writing. Besides, they are still quite motivated and interested in reading Chinese passages/texts. However, the difference begins to emerge as they go up to the secondary stage of their schooling, when their mastery of Chinese falters and lags far behind their local counterparts. Some researchers (Kwan 2014) believe that this lies in the mismatch between the way local students learn and the way these ethnic minority students learn, particularly regarding acquiring reading and writing skills in Chinese.

Since most of the parents of these students are not able to help them in their after class Chinese and in class they are taught the kind of Chinese that is comparable at best to senior primary school level, geared towards sitting GCSE/GCE examinations, it is small wonder that their motivation continues to drop and very soon they will have lost interest in reading and writing Chinese at all. Obviously, something concrete and pragmatic must be done as soon as practicable to improve the situation, to motivate these students in reading Chinese and enhancing their Chinese writing skills. The problem is therefore to hit upon the right ways and means for achieving it.

Furthermore, as pointed out by a number of researchers $(\mathrm{Ku}$ et al.2005; Society for Community Organization 2004) that the lower proficiency level of these young students from ethnic minority backgrounds will seriously affect and even hamper their upward mobility in society in the future, in terms of both their further studies and their career prospects. It is therefore imperative that a solution be found to alleviate the problem situation.

After pondering the problem and looking more closely at how these students learn in the classroom and what teaching and learning materials have been used in their Chinese classes, the research team of this project has reached the following conclusion:

1) The teaching and learning materials for their Chinese classes are basically geared towards enabling these students to sit for the GCSE/GCE Chinese Language Examination, and are thus examination-oriented and quite remote and unrelated to the everyday lives of these students, indeed of most people in Hong Kong. Therefore, there is an urgent need to expose another kind of learning materials to these students, to raise their interest and motivation level. (Furthermore, these GCSE/GCE examinable contents are comparable to the local primary four Chinese in terms of language level.

2) It has been revealed that these students have not been doing much Chinese reading after class, outside the classroom, and it is precisely such kind of supplementary after class reading that is going to help them improve their reading proficiency, and by extension their writing skills and Chinese language proficiency generally.

On the basis of the above observation and conclusion, the research team has designed an on line self-instructional Chinese reading learning and practice package to be placed on a platform for ethnic minority students. This platform is named "EasyRead" and is designed as "One Passage per Day" for students to access, read and practice on the passage on a specified day. If students do not access and work on the given passage on any specific day, the passage will not be available again and the students' progress may be affected. This is intended as a kind of deterrent to students who do not persevere to progress using the system, and on the other hand will enable the more diligent and committed ones to achieve a suitable coherence and running record of their progress and success in the undertaking.

\section{WHAT WE HAVE DONE}

This research adopted an experimental approach for methodology. Ethnic minority students from four participating secondary schools have been grouped as experiment and control teams. The Chinese Reading Practice Package for the students offers short but captivating passages whose subject matter and contents relate closely to everyday lives of these students and of people in Hong Kong generally, so that students will not find it foreign and remote, but instead quite intimate and close to them day in and day out. Volunteering teachers and other members of the research team have been tasked to photograph and video-record various facets and scenes from the everyday lives of common people in Hong Kong on various locations as they engage in various activities and operations. From these resources a series of short but captivating passages have been written, aiming to provide both interesting themes and topics for students' reading pleasure and at the same time enable them to upgrade and raise their Chinese language level step by step as they go along.

Since these students differ tremendously in terms of their Chinese language level, the passages are categorized into six levels. Such a design is intended to cater to different levels and therefore genuine needs of individual students working on the platform, at their own pace and pegging their own level, advancing smoothly as they go along.

It is clear that such a platform is the first of its kind, although there are quite a few online (and off line) self-learning packages on the market, designed and developed quite ably and well by fellow researchers and academics, because the reading passages are authentic from everyday lives of common people 
in Hong Kong, and the language is at the right level for each Level, so that the learner will not be put off or burdened with expressions and structures far beyond their reach, but will instead feel comfortable and rather at home moving on and moving upwards as if sailing on peaceful and safe waters, cruising progressively, making a lot of headway almost imperceptibly and one day soon they will reach the desired goal.

\section{THE WAY FORWARD}

Since launching the platform in January 2017, six months has elapsed and it is therefore time that participating students whose Chinese reading level had been tested before starting on the package should attempt the post-test now. The pre-test and post-test scores will then be processed and analysed to generate data for drawing conclusions for the tiraling and pilot stage of the project.

At the same time, a feedback questionnaire will be administered around this time, six months on since initial launch, to participating students and their Chinese language teachers for their views on using this platform. The responses to this questionnaire will again be processed and analysed for data.

To conclude this stage of the research and to set the next stage for the project, focus group interviews will be conducted with the participating students and their teachers. These focus group interviews will take place twice. The first round will focus on the students' way of life and habits, etc. so as to enrich the content of the reading passages to be incorporated in the near future. The second round will focus on feedback from them on the degree of difficulty of the passages for readjustment.

\section{V.CONCLUSION}

From feedback obtained so far it is evident that this Chinese Reading Platform "EsayRead" has been welcomed by a lot of ethnic minority students who are of the view that the platform really enables them to improve and advance in their second language acquisition, in particular in terms of their reading and by extension writing skills, and they look forward to continuing working on this platform to progress more in the days and weeks to come, confident that they will soon be able to have a good grip of Chinese for their studies and future careers.

A conclusion section is not required. Although a conclusion may review the main points of the paper, do not replicate the abstract as the conclusion. A conclusion might elaborate on the importance of the work or suggest applications and extensions.

\section{ACKNOWLEDGMENT}

The work described in this paper was supported by a grant from the Standing Committee on Language Education and Research (SCOLAR) of the Hong Kong Special Administrative Region, China (EDB(LE)/ P\&R/EU/164/5).

\section{REFERENCES}

[1] Ku, H. B., Chan, K.W., \& Sandhu, K.K., A Research Report on Education of South Asian Ethnic Minority Groups in Hong Kong. Hong Kong : Centre for Social Policy Studies, Department of Applied Social Sciences, the Hong Kong Polytechnic University, 2005 .

[2] Society for Community Organization, A Study of the Nepalese Community in Hong Kong. Hong Kong: Movement Against Discrimination, 2004.

[3] Kwan, C. Y., "The Enigma of the Chinese Language Teaching (non-Chinese speaking students) in Hong Kong”. Current Research in Chinese Linguistics, vol. 93, no.1, 2014, pp.39-57. 